\title{
COMET Intervention: Children's Oral Language Skills as a Key to Literacy Development
}

\author{
Dorota Zolnowska \\ Education Authority, Northern Ireland
}

\begin{abstract}
In 2003 Belfast Education and Library Board introduced an intervention programme COMET (Communication and Education Together) to tackle underdeveloped communication and language skills among primary school children from socially disadvantaged background. As children's language and communication skills can exert a significant influence on their learning as well as their social and emotional development, addressing this issue is of crucial importance. Applying a mixed-methods approach, this longitudinal study evaluates the effectiveness of the COMET intervention and examines its impact on the children's development of oral language skills as well as their reading performance. The quantitative data demonstrated the children involved in the programme had exhibited the higher levels of oral language skills as well as reading and reading-related abilities than the children who had not participated in the intervention. The children involved in the programme improved at a faster rate and had caught up with, or exceeded their peers who had not followed the COMET approach. The effectiveness of the COMET intervention was also confirmed by the qualitative data. The interviews with the principals, literacy coordinators, teachers and learning support assistants revealed that the intervention was an effective, valuable and very informative initiative that was manageable and functioned well in a highly complex and busy school environment. The findings of this study suggest that the COMET intervention is an effective and successful initiative, which not only assists the children in their development of oral language skills and reading abilities, but also positively contributes to reducing the gaps that exists between the children, providing them with a solid foundation and a greater chance for experiencing a school success.
\end{abstract}

\section{Introduction}

The reading process is a complex and challenging task, in which different factors and complicated processes have a significant role to play. Yet, the prominence of reading skills is unquestionable as it provides us with an access not only to education, but also to our culture. A lack of this skill can have dire, far-reaching consequences on future success and lives. Although immense strides have been made in recent years in the field of education to understand the process of learning to read, there still remains a question as to what is the most effective and efficient instruction that equips each child with this crucial skill, and what can be done to facilitate and support the process of mastering the skill of reading. One of the avenues that has been extensively explored is the relationship between oral language and reading, and it has been demonstrated that not only is oral language a key element in the acquisition of the skill of reading, but also developing oral language skills has a positive influence on later literacy performance [1] [2] [3] [4]. Therefore, exploring the associations that exist between children's spoken language competence and their reading acquisition is pivotal as such an analysis can set the patterns for an effective way of approaching the phenomenon of reading [2]. Nevertheless, it is necessary to point out that children differ in their oral language abilities. Their oral language competence and consequently their literacy performance can be influenced by a wide range of factors, such as children's cognitive predispositions and abilities as well as their family background (e.g. socioeconomic status, parental literacy levels). The children's oral language competence is influenced by the quality, quantity and richness of opportunities and interactions for them to foster their oral language development. On the grounds that children's home environments differ enormously from each other in terms of the degree of support and opportunities for promoting both oral language and literacy development, children arrive at school with different set of skills and abilities as well as different experiences. The gaps that exist between the children may impede their progression and consequently they can exert a negative influence on their academic performance. Therefore, it is of crucial importance to provide the children with the instruction that positively contributes to reducing the gaps between children in their oral language development, and consequently provide them with the opportunity to form a solid foundation for their reading development and so increase their chances for school success.

It can be argued that the key element in eradicating children's problems with mastering the reading skills is the early identification of children's shortcomings in oral language development followed by an effective intervention that allows us to address the children's specific needs at the very early stage. 
Having received approval for funding from the Department of Education, in 2003 Belfast Education and Library Board (BELB) introduced an intervention programme COMET (Communication and Education Together) that aimed at providing more efficient and effective support for children with speech and language delays. This innovative intervention focused on promoting a multiprofessional approach (Education: Teachers and Health: Speech and Language Therapists) to effectively support children in their oral language development. The steering committee involved representative from the Department of Education, Department of Health, BELB, North and West Belfast Health and Social Services Trust and South and East Belfast Health Social Services Trust. Having applied the school selection criteria (e.g. 'Targeting Social Need' criteria, school interest in participation), each year the steering committee selected a number of schools in North and West and South and East Belfast to participate in this initiative. There have been approximately sixty-eight primary schools involved in the COMET project since it was implemented in 2003. Each school was provided with the training for the foundation stage teachers and classroom assistants as well as resources and follow-up sessions. Furthermore, approximately twenty-four of these schools were provided with the additional support of COMET learning support assistant during the school year.

BELB implemented the COMET programme to tackle the high number of children entering primary school with underdeveloped communication and language skills. Some of the main aims of the programme were to equip the teachers both with the tools that enable them to identify the children with speech and language difficulties, and the strategies and activities to effectively support these children in the classroom. The programme also aimed at enhancing teachers' confidence in identifying children with speech and language impediments and also raising their awareness of the connections between oral language abilities and literacy acquisition. The COMET programme provided the children with the opportunities to develop their language skills that underpinned the areas outlined in the Northern Ireland Curriculum, such as attention and listening, phonological awareness, social use of language, language and thinking, and vocabulary.

\section{Conceptual framework}

Being a skilled reader is an attribute that affects future life and it is an ability with its roots in early childhood and a lifelong learning curve. Therefore, reading is a formidable area that attracts scholars and educators in many disciplines, who strive to comprehend the reading process and identify its crucial components and factors, so that each child can be effectively supported in gaining this valuable skill and no individual is left behind. It has been pointed out that " 'poor readers' show lower expectations of success, a tendency to give up more easily in the face of difficulty and a tendency to attribute success to external causes such as luck." [5].

Nevertheless, one of the most important preconditions for becoming literate is mastering the language system. It has been pointed out that children must learn the form of spoken language first and gain competency and proficiency in its use, before they can approach the written form of language - reading or writing [6]. The fundamental role of oral language has been also emphasized by Westby, who has argued that "reading and writing are initially dependent on oral language and eventually extend oral language abilities. Young children use their oral language skills to learn to read, while older children use their reading ability to further their language learning - they read to learn" [7]. It can be stated that the role of spoken language in the process of learning to read is prominent, and oral language skills and literacy processes are mutually dependent [1][2]. The mastery of spoken language enables children to take the next developmental step: learning to read. Therefore, acquiring the skill of reading can be perceived as a natural continuation of the child's linguistic development, the next link in the chain of abilities and competencies that are to be gained over the years, to become a fully competent and literate individual.

Oral language acquisition is a complex process that stretches between preschool and elementary years and beyond. Children have to gain control over each aspect of oral language knowledge (phonology, morphology, syntax and semantics, pragmatics as well as vocabulary), so that they can use language appropriately and effectively in particular situations. It also involves listening and speaking, it requires the children to listen to what they hear and interpret what is being said, as well as they need to choose how to express themselves and convey their meaning when they speak. The mastery of all the domains of oral language is crucial, as they not only form the foundation for the acquisition of written language, but also play a very specific role in this process. Written language acquisition is strongly dependent on language knowledge, and its importance has been emphatically emphasized by Menyuk, who has posed the fundamental question: "How can one read what one does not know in oral language?" [8]. The relationship between oral and written language has been also recognised by Juel, who has stated that reading development is strictly related to language development, as it is a natural process that develops due to the need of communication [9]. Therefore, it is believed that increased reading skill derives from 
increased language skill [9]. A strong relationship between reading and other language skills, such as listening, speaking, writing and spelling has been also highlighted by Strang [10]. It has been stated that speech is of primary importance since the degree of mastery of oral language determines the chance of success in beginning reading as "for beginning readers the easiest words to learn are those that are in their speaking vocabulary, arranged in their own sentence patterns, and that have personal significance for them." [10].

Exploring the associations that exist between children's spoken language competence and their reading acquisition is pivotal as such an analysis can set the patterns for an effective way of approaching the phenomenon of reading. It is prudent to point out that "early-emerging oral language capacities and print-based knowledge are related and may mutually facilitate language and literacy development" [11]. It has been demonstrated that the children's lack of control over the ways of applying oral language impedes the process of learning to read, and children with poor oral language skills are at risk of developing reading difficulties [12]. It has been stated that oral language abilities offer a foundation for later reading achievement [2] [3] and it has been pointed out that "oral language skills should be an integral part of reading instruction beginning in preschool and throughout elementary school"'[13]. Research has shown that oral language is a key component in the acquisition of the skill of reading, and developing oral language skills has a positive influence on the later literacy performance [1]. It has been outlined that children's oral language skills not only exert a great impact on their later worddecoding abilities, but also they are related to "phonological sensitivity" which is of utmost importance for the development of reading as "children who are better at detecting and manipulating syllables, rhymes, or phonemes are quicker to learn to read" [14]. It is apparent that oral language skills play a crucial role in the process of learning to read and it has been concluded that “young children's oral language skills may give more information about their academic futures than the traditionally assessed skills in the domains of letter, shape, colour, and number knowledge, or than print-related assessment" [4].

\section{Research Questions}

The main aim of this study was to evaluate the COMET intervention (Communication and Education Together) introduced by Belfast Education and Library Board (2003).

In order to assess the COMET intervention programme it was necessary:

- to examine how children's communication skills help children learn to read;
- to examine the relationship between children's communication skills and their reading development; - to explore whether the intervention was beneficial for children who were having difficulties learning to read;

- to identify and explore the factors that prevented children's success in reading;

- to identify and examine the components of the intervention which enhanced/did not enhance children's success in learning to read.

\section{Method}

\subsection{The sample}

A quasi-experimental design, applying a mixmethods approach was utilized in the research process. The target primary schools were selected for this study using the criteria established by the Department of Education for school selection, based on 'Targeting Social Need' (TSN). TSN criteria had been also applied by BELB to select the schools to participate in the programme each year. On the grounds that the COMET intervention programme had been implemented within the BELB area, the initial phase of the recruitment process involved identification of all the schools in BELB area, which were involved in the programme, so that the experimental groups could be established in the schools willing to take part in the study. The intention of this study was to take the baseline measures before the intervention began, and then track the children's progress over a three-year period with further data being collected annually, at the start and at the end of the school year. In addition, the intention of the study was to identify some matched schools, where pupils were not involved in the COMET intervention and collect data over the same period of time, so they could be used for comparison purposes to assess whether any improvement in performance was a consequence of developmental factors, or the intervention.

Five primary schools were recruited to participate in this study. Three of these schools had been already involved in the COMET Project, the Year One/Year Two teachers had participated in their training scheme; therefore, the experimental groups were established in Year One in these schools. A total of 54 children were involved in the experimental groups and completed the three-year research project (School 1 - 20 children; School 2 - 16 children; School $3-18$ children). Two primary schools, in which the COMET programme was not utilized, involved a total of 31 children (School $4-16$ children; School 5 - 15 children).

Although the research project initially involved 95 children (40 girls and 55 boys), a total of 85 children ( 51 boys and 34 girls) completed the threeyear research project. Over the three year course of 
the project 10 children were eliminated from the study due to their transfer to a different school. There were 54 children involved in the experimental groups and 31 children involved in the comparison groups. The children's age ranged from 4 years and 2 months to 5 years and 1 month, when the project started in Year One. All of the children involved in this study were native English speakers.

The other participants involved in the research project were three school principals, three literacy coordinators, twelve primary school teachers and four COMET learning support assistants, who were interviewed in the final stage of the research project. The teachers' experience in teaching Year One and/or Year Two ranged from 15 months to 22 years.

\subsection{Data collection tools}

4.2.1. The screening measures. Children's communication skills in Year One were measured using individually administered screening tests introduced by Belfast Education and Library Board (BELB): The Profiling Resource (Profiling Communication Skills in Year One - BELB, 2007). The screening was based both on guided observations and specific informal individual assessments. The final scores were marked using a colour-coded system, based on traffic lights, in order to indicate the level of development. For example, a red dot indicated a delay in development in the specific areas, while an orange dot showed some immaturities and highlighted areas that needed to be consolidated; a green dot denoted age-appropriate skills. This method of observation served as an easily-recognisable, quick way to be aware of the pupils' shortcomings in oral development. It gave specific details and information about each child's stages of development as well as it provided clear information about the whole class. The screening lasted approximately thirty-five minutes for each child and was administered in two parts, depending on the child's level of attention and concentration. The screening test battery assessed children's communication skills in the following areas: auditory and visual memory, phonological awareness (syllable segmentation, rhyme judgement/odd-oneout, phoneme blending/segmenting), understanding of language (understanding key words and conceptual language), expressive language (vocabulary, narrative). The child's skills in the areas such as initiation, turn-taking, eye-contact, clarity of speech, and level of attention were established through general classroom observation.

Children's communication skills in Year Two were measured using individually administered screening tests introduced by Belfast Education and Library Board (BELB): The Profiling Resource (Profiling Communication Skills in Year Two BELB, 2007). Similarly to the screening battery utilized in Year One, the screening in Year Two was based on specific informal individual assessments, and the final scores were marked according to the colour-coded system, based on traffic lights, in order to indicate the stages of development. The screening lasted approximately forty minutes for each child. The children's oral language skills were assessed in the following areas: auditory memory, syllable segmentation (final/initial syllable deletion, syllable swap), rhyme awareness (rhyme pairs/odd-oneout/rhyme sort, rhyme generation), phoneme awareness (phoneme blending/segmenting/ deletion), vocabulary (word recall and word definitions), verbal reasoning (problem solving and inferencing).

4.2.2. Outcome measures. In order to measure the language growth and reading skills following the intervention programme two standardized instruments were utilized. Both the experimental and comparison groups completed the Hodder Group Reading Test (2007) which provided the measure of reading comprehension at word, sentence and continuous text levels, as well as the WoodcockJohnson III Diagnostic Reading Battery (2004), which provided the measure of the areas such as phonological awareness, phonics knowledge, reading achievement, and related oral language abilities.

4.2.3. The interview process. One of the aims of this research was to explore various perspective and views on the effectiveness and validity of the COMET intervention programme. Thus, the qualitative research tools were utilized in the research process in order to complement the quantitative data and gain a range of insight on specific issues. There were 22 semi-structured interviews conducted with teachers, literacy coordinators, school principals and learning support assistants in the experimental groups, each lasting approximately 40 minutes. The interviews were audio recorded, so that all views and comments shared could be captured, and were later transcribed for data analysis. The semi-structured interviews provided a unique opportunity for focused, conversational, two-way communication between the researcher and participants. It gave the interviewees the freedom to express their views and opinions in their own terms, as well as it gave the researcher the flexibility to probe for details or discuss issues. Although the researcher followed the list of questions/topics that needed to be covered during the interviews, it enabled to explore other issues that might have diverged from the list of questions/topics, yet they provided new ways of seeing or understanding a particular matter. The following list describes the key areas addressed in the interview process:

- Impact of the COMET programme on children's progress, including the children's reading 
performance as well as other areas identified by the teachers;

- Impact of the implementation of the intervention programme on the teachers' workload;

- Usefulness of the data provided by the language profiles for the teachers, principals, and other professionals working with children;

- Impact of the intervention on teaching and planning;

- Children's participation and engagement in the group work outside the classroom environment;

- Identification of the positive aspects of the COMET programme by the teachers, principals, literacy coordinators, and learning support assistants;

- Identification of the negative aspects of the COMET programme by the teachers, principals, literacy coordinators, and learning support assistantsIn order to be able to make comparisons and draw the main conclusions, the interviewees' responses were grouped into the above-mentioned categories.

\subsection{Procedures}

The evaluation of the effectiveness of the COMET programme involved three main stages. The initial stage of the research involved screening children's English language communication skills in Year One in the experimental groups at the beginning of the school year using The Profiling Resource (Profiling Communication Skills in Year One - BELB, 2007). The information gathered was shared and discussed with the class teachers, who used the data throughout the year to effectively support the children who exhibited weaknesses or delays in particular areas of oral language. The areas targeted by the class teachers during the school year included children's attention and listening skills, auditory and visual memory, phonological awareness, understanding of language, expressive language as well as children's pragmatic skills. Apart from the COMET training, the teachers were provided with the COMET Resource File, which was compiled by the advisory speech and language therapists. It included theory, general strategies and activities for the following language areas: attention and listening, phonological awareness, receptive and expressive language, and pragmatics. It contained materials that could be photocopied for classroom use. The screening of children's English language communication skills was repeated at the end of the school year using the same assessment tool (Profiling Communication Skills in Year One BELB, 2007) to monitor the children's progress and identify the areas that needed specific development. The first stage of the research involved taking the baseline measure of children's communication skills in the experimental groups only as the comparison groups did not grant their permission to participate in the study for three years. The comparison groups completed the subsequent measures and test.

The second stage of the research involved the analysis and interpretation of the results of the reassessments, as well as identification of children who demonstrated a delay in the development of particular language areas at the start of Year Two. Moreover, a baseline measure of children's English language communication skills was taken at the beginning and at the end of Year Two both in the experimental and comparison groups using The Profiling Resource (Profiling Communication Skills in Year Two - BELB, 2007). The second stage of the research also involved implementation of the COMET programme in the experimental groups. The children who displayed delays in the development of certain language areas were identified and divided into small groups, and an appropriate plan of intervention was designed. The session plans were created with the support of the speech and language therapist in order to effectively address the children's specific needs (records were kept of the materials used and activities of each of the groups as well as children's performance). The areas targeted during the intervention process included children's attention and listening skills, memory, phonological awareness, vocabulary, verbal reasoning and pragmatic skills. It also involved speaking and listening (e.g. conversations and group discussions, developing the ability to convey ideas and information verbally as well as developing the ability to listen and respond appropriately to each other). The children's progress could be easily monitored as the intervention was structured into six-week blocks and the targets were set for each block. After having completed the six-week cycle the children involved in the groups were reassessed using the Profiling Resource (Profiling Communication Skills in Year Two - BELB, 2007) to check if the aims were achieved. The pupil composition of the groups was reviewed every six weeks and altered during the intervention based on improvement levels. The progress of the children involved in the intervention programme was discussed with the class teachers on regular basis as well the whole-class targets were identified, so that the children's particular needs were also met in the classroom environment by the teacher and learning support staff. The children's specific language areas were not only targeted in the small group outside the classroom, but they were also consolidated and reinforced by the class teacher. The intervention was scheduled for a whole school year and each group was seen once a week for thirtyfive minutes. There were a total of 14 groups seen every week in three primary schools, each group consisted of 4-5 children. The whole-class screening was repeated at the end of the school year in June 2013 and the data gathered were given to the Year Three teacher. 
The third stage of the research involved the assessments of children's reading skills both in the experimental and comparison groups (Hodder Group Reading Test, 2007; Woodcock-Johnson III Diagnostic Reading Battery, 2004) in order to evaluate the impact of the COMET intervention on their reading performance.

\section{Findings}

The findings of the research project clearly suggest that applying this multi-professional approach (Education - Teachers and Health - Speech and Language Therapists) to develop an intervention seemed to be an effective way of supporting children in developing their communication skills, which later impact on their reading - related abilities and reading performance. The pupils who participated in the COMET intervention programme outperformed a matched comparison group of pupils who were not following the COMET approach in several areas, as demonstrated by their performance on the COMET baseline: Profiling Communication Skills in Year Two (BELB, 2007) completed at the end of Year Two, as well as the Woodcock-Johnson III Diagnostic Reading Battery (2004) completed in Year Three.

Having analyzed the data collected at the beginning and at the end of the school year both in the experimental and comparison groups, it was demonstrated that despite the fact that the level of communication skills of the children in the COMET groups was lower than the comparison groups prior to the intervention (see Table 1), the children who were involved in the programme were able to match or excel their peers' results following the intervention programme (see Table 2). The COMET groups showed particular strengths in the areas measured at the end of the school year in Year Two, such as rhyme odd-one-out, rhyme sort, rhyme generation, phoneme segmenting, phoneme deletion, word recall, and word definitions.

Table 1. The comparison of the children's oral language skills before implementation of the COMET intervention in Year Two

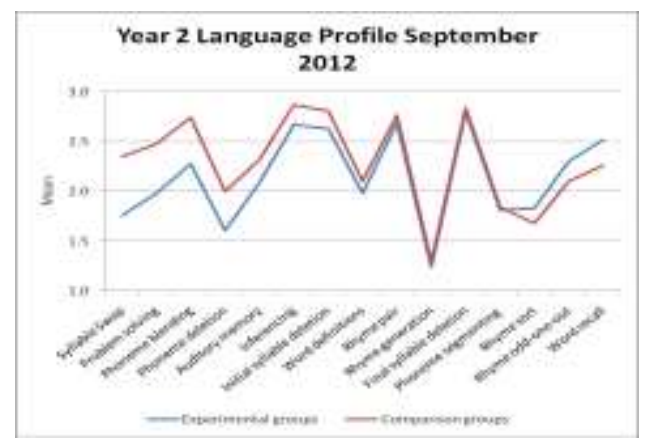

Table 2. The comparison of the children's oral language skills following the intervention programme

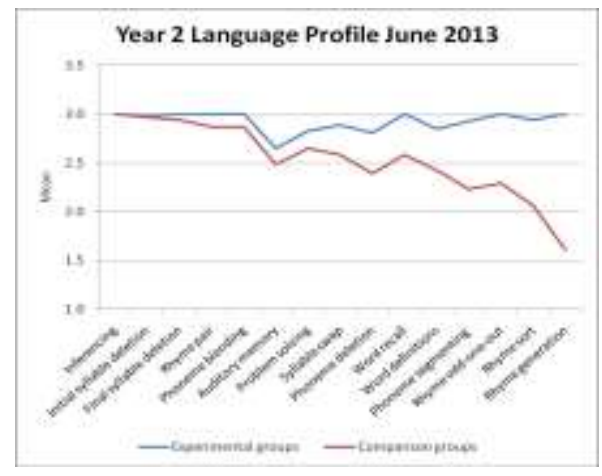

Furthermore, the evidence suggested that the COMET intervention programme contributed to the significant growth of the children's sound awareness, sound blending, phonics knowledge, phonemic awareness, oral vocabulary, oral language comprehension, and word attack, all of which were measured in Year Three (see Table 3). The findings suggest that participation in the intervention programme as well as addressing and focusing on the children's individual, specific needs through the small group work, was beneficial for all the pupils involved, as it effectively assisted them in developing their oral language skills, and other reading-related abilities.

Table 3. The results of the reading test completed in Year Three

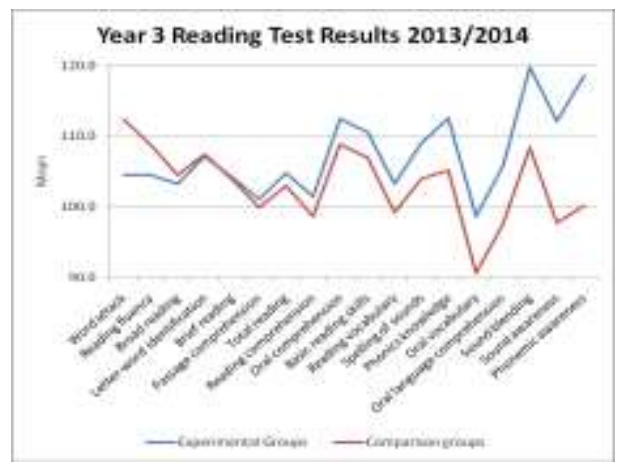

In order to provide evidence whether the intervention was beneficial for all children or the children with poor communication skills and to investigate whether the assessment instruments employed during the intervention process were an effective method of identifying children, who might be at risk of developing reading problems, the secondary data analysis was conducted. The data collected on entry to Year Two both in the experimental and comparison groups were used to identify children for subgroup analysis. The children's oral language skills were established in fifteen different areas at the 
beginning of the school year, the children who displayed a delay in development in six or more areas were identified (see Table 4). A total of 41 children were selected for the subgroup analysis (29 children were selected from the experimental groups and 12 children were selected from comparison groups).

Table 4. The comparison of the oral language skills of the Year Two children who were identified as 'atrisk' of having difficulties learning to read (prior to the COMET intervention)

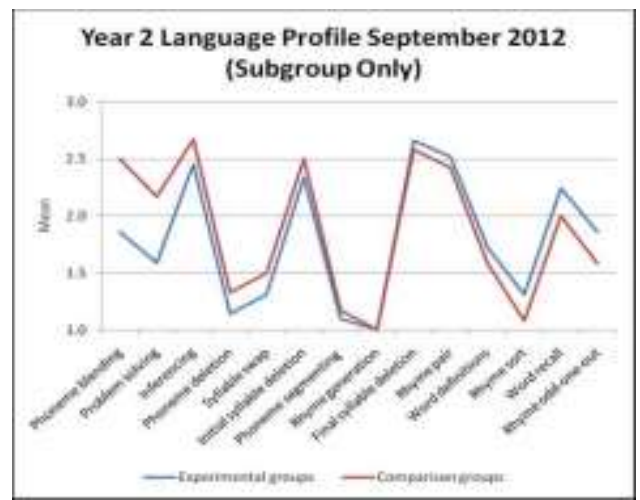

The findings from the analysis of a subgroup of pupils who appeared to be particularly 'at risk' indicated that not only the COMET screening was a useful and efficient tool that enabled the researcher to identify the children who might be 'at risk' of having difficulties learning to read, but also participation in the intervention programme was beneficial for those pupils who were identified as at risk of having problems learning to read. Owing to the fact that the areas of weaknesses were identified and highlighted at the early stage and the appropriate targeted support was provided, those children exhibited significant improvements, in comparison with the non-COMET children, in various areas following the intervention program. The particular gains were observed in the areas tested at the end of Year Two (see Table 5), namely syllable swap, rhyme odd-one-out, rhyme sort, rhyme generation, phoneme segmenting phoneme deletion, word recall, word definitions, and problem solving.

Furthermore, the intervention positively contributed to increasing their skills in the areas measured in Year Three (see Table 6), such as word attack, reading vocabulary, sound awareness, sound blending, oral vocabulary, oral comprehension, phonics knowledge, phonemic awareness, and oral language comprehension.

As part of a triangulation strategy, the implementation of the COMET intervention approach was also explored through the collection and analysis of qualitative data, all of which seemed to confirm the quantitative data as to the efficacy of the programme.

Table 5. The comparison of the oral language skills following the intervention programme

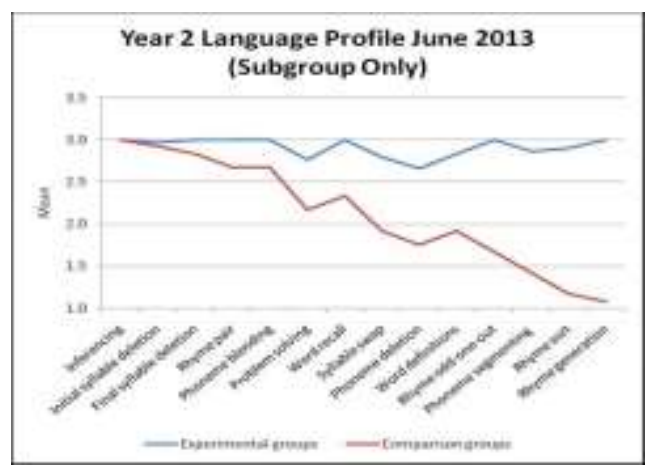

All of the interviewed primary school teachers unanimously agreed that the COMET intervention contributed to the children's performance and positively influenced their way of teaching. The teachers perceived the COMET programme as a very useful and informative tool, which enabled them to gain insight into the levels of children's oral language abilities.

Table 6. The comparison of the results of the reading test completed in Year Three

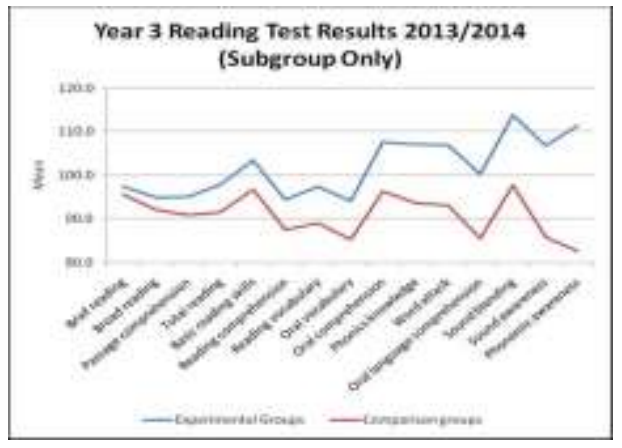

It was pointed out that because of the fact that the early literacy skills were clearly divided into specific areas during the intervention process, the areas of weakness and delays were quickly identified and highlighted, providing the teachers with a very clear focus and enabling them to meet children's individual needs. It was stated that the COMET assessment tools were the quickest, fastest, and the most clear-cut way of recording difficulties. They not only assisted the teachers with very clear target setting and helped to monitor the children's progress throughout the year, but also provided the teachers with valuable information about the level of abilities of the whole class as well as individual pupils, which could then be easily shared with other teachers, as well as the external agencies providing additional support in school, and parents, if needed. The 
COMET assessment tools were considered to be very clear, concise, and easy to administer and follow. Furthermore, the children found the whole project an enjoyable experience, the testing was carried out in a very "fun" manner; there was no feeling of test procedure or pressure in it.

All of the interviewed teachers recognized the positive impact of the COMET intervention programme on the children's reading performance. Both the Year One and Year Two teachers pointed out the advantages of focusing on the pre-reading skills, working on children's phonological awareness and vocabulary, as well as concentrating on children's attention and listening skills, and turntaking; as all these aspects supported children in becoming successful and confident readers. It was also highlighted that the COMET programme could be easily implemented into the everyday teaching as it complemented the reading schemes used in the classrooms.

The other aspects/areas that were listed by the teachers as being influenced by the COMET intervention programme were the children's attention and listening skills, language and communication skills, pragmatic skills such as eye-contact, turntaking, initiation, interaction with peers as well as children's confidence and self-esteem (children were more willing to participate in discussions and other whole-class based activities following the intervention programme).

Having explored the impact of the implementation of the intervention programme on the teachers' workload, it was stated that stated that the intervention programme did not have any impact on their workload (67\% of the interviewed teachers). It was pointed out that the assessment tools utilized during the intervention process not only provided valuable information about the children's abilities, but actually eased their workload and made it more structured and clearer. The COMET activities were easy to incorporate throughout the school days, as they complemented what was being taught. $8 \%$ of the interviewed teachers claimed that it was manageable, yet they had to depend strongly on a classroom assistant/other teacher while carrying out the assessments. On the other hand, $8 \%$ of the interviewed teachers felt that participation in the intervention programme initially increased their workload, as they had to familiarize themselves with the assessment tools and resources, however after a while they felt confident and they were able to adapt it very quickly and very efficiently into everyday teaching. $17 \%$ of the interviewed teachers said that their workload was increased due to the participation in the intervention programme, yet it was valuable for their planning and target setting, therefore worth doing.

It became clear that the changes were made by the teachers both in their ways of teaching and planning as a result of the participation in the COMET intervention programme. It was pointed out that their participation in the programme raised the teachers' awareness of the crucial role and importance of the children's oral language skills and the impact they have on the children's academic performance. It helped the teachers realize that sometimes they were moving too fast, not building on the foundations and assuming that the children had already acquired certain skills. Having the COMET data resulted in catering for children's specific needs and spending more time on developing children's language and communication skills. As far as changes in the planning were concerned, the teachers claimed that participation in the programme and having the COMET data, had a positive influence on their planning, as it gave them a better structure as to what to do and when to do it, making the planning clearer.

The interviewed principals and literacy coordinators viewed the intervention programme as a valuable learning experience for the children, the small-group work provided targeted support and rich learning opportunities, especially for those who exhibited poor communication skills and who struggled in the classroom environment. It was pointed out that the COMET strategies and activities were not only embedded practice both in Year One and Year Two, but also that the programme fitted well into the whole-school practice, as it worked in conjunction with literacy schemes, and in accordance with the Northern Ireland Curriculum, providing opportunities for effective learning. The data gathered gave the principals and literacy coordinators a picture of what was happening in the classrooms, the levels of children's abilities, and how they were progressing.

Overall, the COMET approach was considered to be very useful and informative as it provided detailed information about each child, which enabled everyone concerned to meet the children's individual needs, and equipped them with the skills that formed solid foundation for their reading development. Both the quantitative and qualitative findings suggest that the COMET intervention programme positively contributed to the pupils' development of oral language skills and reading ability. Furthermore, such an approach seemed to be an effective way of accessing the curriculum.

\section{Discussion}

The reading process and its acquisition is a longlasting and time-consuming process, and becoming a proficient reader entails the development and mastery of a wide variety of skills and abilities, in an interactive and simultaneous manner. One of the strands that has been considered a foundation and crucial for literacy development, and has been 
extensively investigated is oral language proficiency. Language deficits can have dire consequences on the children's reading performance, in particular reading comprehension [15] as well as they can underlie the children's reading difficulties [16] [17].

The COMET intervention programme significantly contributed to enhancing children's oral language skills and oral language comprehension. Due to the fact that a strong relationship between linguistic comprehension and reading comprehension has been reported in the literature [18] the evidence from this study not only carries particular significance, but also suggests that the COMET intervention may be an effective method of enhancing children's oral language comprehension. Catts, Hogan and Fey have showed that language comprehension deficiency can exert constant and persistent pressure on the children's reading comprehension abilities [15]. Furthermore, research has shown [19] that the appropriate intervention programmes aimed at developing the children's oral language proficiency can contribute to addressing the needs of diverse learners and assist the children in enhancing their literacy skills that are necessary for school success.

Contrary to expectations, the present study did not find a significant difference in reading comprehension abilities between the COMET and comparison groups. This may have been a consequence of the fact that there was a considerable gap between the COMET and comparison groups, with the former achieving lower scores, in terms of their oral language abilities prior to the intervention programme. The children involved in the programme made excellent progress in the development of their oral language skills and oral language comprehension, which was demonstrated by their ability to match or excel their peers' results following the intervention programme. However, while the COMET groups were characterized by higher scores on the reading comprehension test than the comparison groups, the observed differences between the groups in this study were not significant. There was some evidence of improvement, however, and it may have reached statistically significant levels if the baseline position for both groups had been more similar. It is also possible that reading comprehension may be a more challenging proposition and thus requires higher, or longer, periods of intervention.

Furthermore, the COMET intervention approach meaningfully contributed to the growth of children's vocabulary. All of the children involved in the intervention programme exhibited increased level of abilities in word recall and word definitions at the end of Year Two and were characterized by a greater oral vocabulary in Year Three. Moreover, the children who were identified as having poor oral language skills prior to the implementation of the intervention, showed significant increases in both their oral and reading vocabulary in Year Three. This observation may support the hypothesis that boosting children's oral vocabulary and oral expression results in increasing their reading skill [1] [8] [10]. As it was explicitly pointed out by Strang [10] and Menyuk [8] oral vocabulary strongly influences reading vocabulary for reading beginners, the children need to learn words first and they need to be able to use them in their oral expressions, so that the process of learning to read these words can be facilitated.

Vocabulary knowledge is considered to be a crucial element in the process of learning to read. It has been suggested that vocabulary knowledge may be a significant factor for learning to recognize printed words [20] as well as it may play an important role in the comprehension of text [21]. On the grounds that vocabulary differences between children can be considerable, they can arise from early years, and there is the tendency that this vocabulary gap widens over time [19] it is of crucial importance that the children are provided with multiple vocabulary learning opportunities, so that the gap between the children with poor and rich vocabularies can be effectively reduced. Baker, Simmons and Kameenui have called for " $a$ much more active and vigorous educational commitment to increasing the vocabulary growth of diverse learners who often experience vocabulary problems and delays" [19]. Similar argument has been put forward by Beck and McKeown [22] who stated that although large and rich vocabulary knowledge is crucial for reading proficiency and the gaps between learners in their vocabularies can be significant, it is an area that has not been receiving adequate attention in schools. They have highlighted the importance of the instruction that provides children with sophisticated words, which enhances their vocabulary knowledge, stating that " a key aspect of the argument for teaching young children sophisticated words is that the earlier word meanings are learned, the more readily they are accessed later in life" [22].

The COMET intervention approach was an effective way of enhancing the children's oral language skills and oral language comprehension. The integration of numerous vocabulary learning opportunities in the programme led to increases in the pupils' vocabulary knowledge. On the grounds that oral language proficiency is crucial for children's literacy development, and consequently schools success, these results provide further support for the hypothesis that helping children to overcome their weaknesses in oral language skills enables them to acquire strong beginning reading skills, so that they can engage successfully in various learning opportunities. It can thus be suggested that participation in the intervention programme enabled the children to improve their poor oral language 
skills that posed limitations for their further literacy development.

Furthermore, the COMET intervention approach exerted an appreciable influence on the children's phonological awareness. The importance of phonological awareness in the process of learning to read has been noted in prior studies [23] [24]. Goswami and Bryant [23] have claimed that early phonological skills are of crucial importance in the process of learning to read, as good awareness of rhymes and other units of speech can lay the foundation for future beginning reading strategies; thereby, putting the children at an advantage in the early stages of acquiring reading skills. It has been pointed out that phonological skills encourage reading development by enabling the children to recognize and apply orthographic analogies when they come across an unfamiliar word [23].

Moreover, it has been pointed out [23] [24] that not only good phonological awareness and sensitivity to onset - rime units in speech facilitate the process of learning to read, but such awareness is also considered to be a developmental precursor of children's development of phoneme awareness. It is interesting to note that a similar pattern emerged from the data analysis, namely the children who were involved in the intervention programme and who exhibited improvements in their awareness of onset and rime, also demonstrated increases in the phoneme segmentation and phoneme manipulation skills at the end of Year Two. Furthermore, they also demonstrated significant gains in their sound blending skills in Year Three, as well as in their phonics knowledge and phonemic awareness. Another important finding was that these children performed better on a word attack task in Year Three in comparison with the children from non-COMET groups. These results support previous research into the development of word recognition which links the importance of onset - rime and phoneme sensitivity [23] [24]. Although, there has been a disagreement on which skill is a better predictor of word recognition abilities [25], it has been argued [26] that onset - rime awareness is an important element in the process of learning to read, as it influences children's reading directly by encouraging the application of orthographic analogies, as well as it makes a contribution indirectly by serving as the basis for development of phoneme awareness, which then in turn exerts an impact on the children's reading performance. According to Bryant "the important question is not whether the direct route is viable, but when (which may be affected by teaching practices) and how it begins to work" [26].

The results clearly demonstrated that all of the children involved in the intervention programme benefited from it. It had a direct impact on the improvement of their oral language skills, as well as it influenced their reading and reading - related skills. Nevertheless, it is necessary to note that the impact of the intervention appeared to be even more significant for a subsample of pupils with poor oral language. These children were characterized by the lower levels of oral language skills prior to the implementation of the COMET programme; however, the pattern of results was completely different following the intervention. The children involved in the COMET programme not only improved at a faster rate, but also exceeded their non-COMET peers in all of the areas measured at the end of Year Two and in Year Three.

A possible explanation for these positive results might be the fact that the children who arrived at school with weaknesses in their oral language abilities were identified at the very early stage and their particular needs were met by the targeted, wellstructured support. The children's progress was regularly monitored during the intervention process, and the information was shared with the class teacher on regular basis, which enabled the researcher to provide the children with a tailored programme that addressed their specific needs both in the classroom and outside the classroom environment. Participation in the COMET intervention allowed the children to meaningfully reduce the gap in their oral language skills, which posed limitations for the development of strong beginning reading skills. Furthermore, one of the important findings to emerge from the qualitative analysis is that through the small-group work the children not only improved their oral language skills which exerted impact on their reading and reading - related performance, but they also acquired additional skills and confidence that enabled them to engage successfully in whole-class, curriculum-based activities. These findings suggest that all children can benefit from participation in the COMET intervention, yet such an approach seems to be even more beneficial and effective for the children who arrive at school with some deficiencies in their oral language development as they place them at risk of developing reading difficulties. A significant group of children who exhibit reading problems is hypothesized to have significant deficiencies or impairments in language which can be observed as early as the preschool years [16] [17], therefore supporting the children, who lag increasingly behind their peers in terms of their oral language development, through an effective intervention seems to be an appropriate method of increasing their chances of experiencing school success.

It is possible to state that the fundamental factor negatively affecting children's literacy development was linked to the children's poor oral language abilities. The results of this research support the idea that providing training both in phonological and phonemic awareness for children who demonstrate deficits in these aspects as well as focusing on 
enhancing children's language comprehension skills and strengthening their vocabulary, can have a positive influence on their development of beginning reading skills. It is encouraging that these results dovetail with what has been learned from research on the relationship between oral language skills and reading development.

Scarborough has rightly pointed out that becoming a skilled reader involves mastering two strands, namely language comprehension and word recognition [16]. The language comprehension strand includes background knowledge, vocabulary, language structures, verbal reasoning, and literacy knowledge; whereas word recognition involves phonological awareness, decoding and sight recognition. These two strands are inextricably intertwined with each other and they are the factors conditioning fluent and effective performance of word recognition and comprehension of the text [16]. On the grounds that the COMET intervention approach focuses on the development of a wide range of oral language skills that form the solid foundation both for decoding and comprehension, through their participation in the intervention, the children can be better equipped with the fundamental skills which later can help them to be better prepared for reading instruction.

Another interesting finding to emerge from the qualitative analysis is that the children's poor attention and listening skills often hindered their progress in acquiring reading skills. The lack of these skills made it hard for children to attend and concentrate during the reading practice, which made them lag behind their peers in reading achievement. It has been demonstrated that reading difficulties among the youngsters are often associated with attention deficits [27]. On the grounds that this aspect plays an important role in literacy acquisition, one of the focus areas of the COMET programme was in developing children's attention and listening skills. The impact of the children's improvements in these areas was greatly recognized by the teachers, who concluded that through their participation in the programme, children were equipped with the skills that got them ready to read. Due to the fact that good attention and good listening are the prerequisites for effective learning, lack of those skills has a tremendous impact on their performance. It was pointed out by the teachers that developing children's attention and listening skills through small group work had a significant impact on the children's performance in the classroom environment. The children were able to pay attention, listen to what the teacher and other children were saying, follow the instructions successfully, and while reading they were able to concentrate, follow the words with their fingers, turn the pages at the appropriate time, and listen attentively to their peers' reading. It was highlighted by the teachers how important it was for the children to master these skills before they could even read a word.

The results of this research also highlight the importance and benefits of focusing on the development of children's syntax and semantic skills, as well as pragmatic abilities. It can be stated, based both on the researcher and teachers' observations, that the children involved in the intervention programme exhibited improvements in these three areas, which later impacted on their performance in the classroom environment. Vasilyeva, Huttenlocher and Waterfall [28] have pointed out that syntactic proficiency can have a broad influence on children's school performance, and deficiencies in this area can have negative impact on their reading development [29]. Nevertheless, it has been pointed out that apart from syntactic awareness, children also have to acquire semantic abilities as they can influence both word recognition [30] and comprehension [31]. The evidence from this study also indicates that the COMET intervention approach contributed to the children's development of pragmatic skills, namely the teachers observed increased expertise in the children's use of conversational skills, such as initiation, turn-taking, topic development and topic maintenance, as well as eye-contact. Furthermore, the children demonstrated higher competence in the production of conventional speech acts following the intervention programme. On the grounds that pragmatic competence is crucial for the development of confidence, precision and proficiency in language use [8], these results are very encouraging. This combination of findings suggests that the success and effectiveness of the COMET intervention programme is underpinned by the fact that it helps to address a wide range of children's oral language and communication skills, and its structure and organization allows it to be tailored to meet the children's specific needs.

Although the results of the study enabled the researcher to identify the components of the intervention programme that positively contributed to the children's success in learning to read, there were some areas of the COMET language profile which did not demonstrate significant differences between the children's scores following the intervention programme. These areas included final/initial syllable deletion, rhyming pairs, sounds blending, and inferencing. In spite of the fact that the children involved in the programme showed higher scores on the tasks such as final/initial syllable deletion, rhyming pairs, and sounds blending, these results were not statistically significant. As far as the inferencing test is concerned, both the COMET and comparison groups were characterized by relatively similar scores in this area at the beginning of this study and there was no difference found between the 
groups following the intervention programme. There are three possible explanations for these results. First, it might be that any improvement in performance in these particular areas was a consequence of developmental factors, not the intervention. Second, it seems also plausible that the differences between the groups could be more visible if a bigger sample size was involved. Third, this result may be explained by the fact that the tests used were not sensitive enough to observe differences between the children's skills.

Taken together, the findings of this study are both encouraging and promising, as they indicate that the COMET intervention approach is an effective initiative that promotes the development of children's oral language and communication skills and enhances the development of reading and reading related abilities. The COMET assessment tools prove to be an efficient method of identifying children with poor oral language skills who might later be at risk of having difficulties learning to read. The completed COMET language profiles, which display children's strengths and weaknesses in their oral language development, are considered to be a very useful and valuable source of information that is effectively utilized in the school environment by the teachers and other professionals working with children. On the grounds that the COMET intervention programme is curriculum-based, it provides training sessions for the teachers, its guidelines are clear and easy to follow; it can be therefore suggested that it is an initiative that can not only be effective, but also sustainable in the complex school environment.

\section{Conclusion}

The combination of findings from this study provides some support for the premise that the COMET intervention programme was a successful and effective initiative. Its focus on enhancing the development of oral language skills enabled the children to improve in a wide range of language skills at a faster rate, in comparison with a matched sample of pupils not undertaking COMET. The COMET intervention provided the children with multiple learning opportunities, and thus appeared to contribute to forming a solid foundation for their reading development. On the grounds that oral language is a key element in the process of learning to read and developing oral language skills has a positive impact on the later literacy development [1], [2], [3] and [4], supporting children with poor oral language skills seems to be an effective way of reducing the gap between children's abilities, and thereby raising their chances of experiencing success at school. Muter at al. have aptly expressed the importance of oral language in reading development, stating that "reading is a linguistic skill that, with rare exceptions, is learned only after children have acquired considerable proficiency in oral language" [32].

\section{References}

[1] MacDonald C., Figueredo L. Closing the Gap Early: Implementing a Literacy Intervention for At-Risk Kindergartners in Urban Schools. The Reading Teacher. 2010; 63 (5): $404-420$.

[2] NICHD Early Child Care Research Network. Pathways to Reading: The Role of Oral Language in the Transition to Reading. Developmental Psychology. 2005; 41: 428 - 442.

[3] Roth F., Speece D., Cooper D., A Longitudinal Analysis of the Connections between Oral Language and Early Reading. The Journal of Educational Research. 2002; 95: $259-272$.

[4] Snow C., Tabors P., Nicholson P., Kurland B., SHELL: Oral Language and Early Literacy Skills in Kindergarten and First Grade Children. Journal of Research in Childhood Education. 1995; 10(1): 37 - 48.

[5] Pumfrey P., Reason R., Specific Learning Difficulties (Dyslexia). Challenges and Responses. London: Routledge; 1991.

[6] Richardson S. Evolution of Approaches to Beginning Reading and the Need for Diversification in Education, in Ellis W. (Ed.). All Language and the Creation of Literacy. Baltimore, Maryland: The Orton Dyslexia Society; 1991:1 $-8$

[7] Westby C., Assessing and Remediating Text Comprehension Problems, in Catts H. and Kamhi A. (Eds.) Language and Reading Disabilities, Pearson Education; 2005:157 - 232.

[8] Menyuk P., Language Development and Reading, in Flood J. (Ed.). Understanding Reading Comprehension: Cognition, Language, and the Structure of Prose. Newark, DE: International Reading Association; 1984: 101 - 121.

[9] Juel C., Beginning Reading, in Barr R, Kamil M, Mosenthal P, Pearson P. (Eds.). Handbook of Reading Research. Volume II, New Jersey: LEA, Inc.; 1996: 759 785.

[10] Strang R., The Nature of Reading, in Chapman L, Czerniewska P. (Eds.). Reading from Process to Practice. London: Routledge \& Kegan Paul Ltd; 1978: 61 - 94.

[11] Dickinson D., Sprague K., The Nature and Impact of Early Childhood Care Environments on the Language and Early Literacy Development of Children from LowIncome Families, in Neuman S, Dickinson D. (Eds.) Handbook of Early Literacy Research. New York: The Guilford Press; 2003:263 - 280.

[12] Menyuk P., Chesnick M., Metalinguistic skills, oral language knowledge, and reading. Topics in Language Disorders. 1997; 17(3): 75 - 87. 
[13] Storch S., Whitehurst G., Oral Language and CodeRelated Precursors to Reading: Evidence from a Longitudinal Structural Model. Developmental Psychology. 2002; 38(6): 934-947.

[14] Lonigan C., Burgess S., Anthony J., Development of Emergent Literacy and Early Reading Skills in Preschool Children: Evidence From a Latent-Variable Longitudinal Study. Developmental Psychology. 2000; 36 (5): 596 613.

[15] Catts H., Hogan T., Fey M., Subgrouping Poor Readers on the Basis of Individual Differences in ReadingRelated Abilities. Journal of Learning Disabilities. 2003; 36(2): $151-164$.

[16] Scarborough H., Connecting Early Language and Literacy to Later Reading (Dis)abilities: Evidence, Theory, and Practice, in Neuman S, Dickinson D. (Eds.) Handbook for Research in Early Literacy. New York: Guilford Press; 2001: $97-110$.

[17] Hulme C., Snowling M., The Interface between Spoken and Written Language: Developmental Disorders. Philosophical Transactions of the Royal Society B. 2014; 369: 20120395.

[18] Hoover W., Gough P., The Simple View of Reading. Reading and Writing. 1990; 2: 127 - 160.

[19] Baker S., Simmons D., Kameenui E., Vocabulary Acquisition: Instructional and Curricular Basics and Implications, in Simmons D, Kameenui E. (Eds.) What Reading Research Tells Us about Children with Diverse Learning Needs: Bases and Basics. Mahwah, NJ: Erlbaum; 1998: $219-238$

[20] Nation K., Snowling M., Individual Differences in Contextual Facilitation: Evidence from Dyslexia and Poor Reading Comprehension. Child Development. 1998; 69(4): $996-1011$.

[21] Nation K., Snowling M., Developmental Differences in Sensitivity to Semantic Relations among Good and Poor Comprehenders: Evidence from Semantic Priming. Cognition. 1999; 70:B1 - B13.

[22] Beck I., McKeown M., Increasing Young LowIncome Children's Oral Vocabulary Repertoires through Rich and Focused Instruction. The Elementary School Journal. 2007; 107(3): $251-271$.

[23] Goswami U., Bryant P., Phonological Skills and Learning to Read, Hove, East Sussex, England: Erlbaum; 1990.

[24] Bryant P., MacLean M., Bradley L., Crossland J., Rhyme and Alliteration, Phoneme Detection, and Learning to Read. Developmental Psychology. 1990; 26(3): 429 438.

[25] Hulme C., Hatcher P., Nation K., Brown A., Adams J., Stuart G., Phoneme Awareness is a Better Predictor of Early Reading Skill than Onset - Rime Awareness.
Journal of Experimental Child Psychology. 2002; 82(1): 2 -28 .

[26] Bryant P. It doesn't Matter whether Onset and Rime Predicts Reading Better than Phoneme Awareness or Vice Versa. Journal of Experimental Child Psychology. 2002; 82(1): $41-46$

[27] Cain K., Bignell S. Reading and Listening Comprehension and their Relation to Inattention and Hyperactivity. British Journal of Educational Psychology. 2014; 84(1): 108 - 124.

[28] Vasilyeva M, Huttenlocher J, Waterfall H. Effects of Language Intervention on Syntactic Skill Levels in Preschoolers. Developmental Psychology. 2006; 42(1):164 $-174$.

[29] Nation K., Snowling M., Factors Influencing Syntactic Awareness Skills in Normal Readers and Poor Comprehenders. Applied Psycholinguistics. 2000; 21(2): $229-241$

[30] Nation K., Snowling M., Semantic Processing and the Development of Word-Recognition Skills: Evidence from Children with Reading Comprehension Difficulties. Journal of Memory and Language. 1998; 39(1): 85 - 101.

[31] Myers J., O'Brien E., Accessing the Discourse Representation during Reading. Discourse Processes. 1998; 26(2-3):131 - 157 .

[32] Muter V., Hulme C., Snowling M., Stevenson J., Phonemes, Rime, Vocabulary, and Grammatical Skills as Foundations of Early Reading Development: Evidence from a Longitudinal Study. Developmental Psychology. 2004; 40(5): $665-681$. 